\title{
Apresentação
}

Cesar Augusto Barcellos Guazzelli*

Arthur Lima de Ávila**

\section{"Quem será o americano, este novo homem"? (Ou quantas Américas cabem na América?)}

\section{Uma outra América, um país sem nome!}

Os Estados Unidos da América (EUA) constituem um estranho país! Para iniciar, trata-se de um país "sem nome"! O historiador Leandro Karnal - da Universidade Estadual de Campinas (UNICAMP) - salientou, numa conferência proferida em nossa universidade, em 2010, ${ }^{1}$ que todos os países americanos têm nomes: eles podem ser associados a heróis nacionais (Bolívia, Colômbia), a acidentes geográficos (Uruguai, Paraguai), aos nomes que tinham estes territórios antes da conquista (Chile, México), ou a produtos identificados com os lugares (Argentina, Brasil). Os Estados Unidos, ao contrário, originários das Treze Colônias, pertencentes ao Reino Unido, constituíram-se em estados, resguardando suas autonomias,

\footnotetext{
* Professor Titular do Departamento de História e do Programa de Pós-Graduação em História da Universidade Federal do Rio Grande do Sul (UFRGS). ** Professor Adjunto do Departamento de História e do Programa de Pós-Graduação em História da Universidade Federal do Rio Grande do Sul (UFRGS).
} 
tendo como referência o continente - a América, que lutava pela independência - em oposição a uma opressão que vinha da Europa.

O país "sem nome" adotou como seu um nome que incluía outras terras e povos! É raro escutar de um estadunidense, referindo-se ao seu país, a expressão United States; bem mais comum é o uso da abreviatura U.S.A., pronunciada rapidamente, letra por letra. No entanto, America é, desde a Revolução de Independência, uma referência tão forte que mesmo os americanos de outros países se referem aos estadunidenses como "americanos" ou pelo menos "norte-americanos".

Mas o país, se não tinha um nome, construiu seus símbolos identitários e implementou processos políticos e sociais que lhe trariam a condição de superpotência apenas um século e meio depois de sua criação. E desde o início a formação do Estado nacional foi garantida a partir de unidades autônomas - os estados sucedâneos às colônias originais - que delegaram a um poder constituído na forma de uma federação. ${ }^{3}$ Muito antes disso, porém, já havia sido criada a representação máxima da nação, a bandeira. Primeiramente uma bandeira clandestina que representava as colônias por listras alternadas vermelhas e brancas, adotada por Washington, em 1776, mas ostentando no quadrante superior esquerdo o desenho da bandeira britânica, substituído definitivamente pelo retângulo azul, com as estrelas simbolizando os estados, criada pela lei de quatorze de junho de 1777. Deram-lhe nomes: Stars and Stripes, descritivo; Old Glory, apologético!

Esta marca inconfundível dos Estados Unidos ainda não tinha cem anos quando foi negada pelos rebeldes sulistas que fizeram a secessão dos Estados Confederados da América. Criaram sua própria bandeira, com fundo, listras e estrelas noutro arranjo. E ela é ainda hasteada em estados do Sul, muitas vezes de forma contraditória, ao lado do estandarte da União. Além disso, foi parodiada por Mark Twain, que compôs um estandarte de listras vermelhas e negras, ostentando num retângulo preto caveiras, ao invés das estrelas; para ele, a nação da liberdade convertera-se num entreposto da pirataria mundial.

Outra glória máxima da nação é o hino! Além do hino dos Estados Unidos, de 1814, tornou-se muito popular outra composição, God Bless America (Deus Abençoe a América), de Irving Berlin, que a partir de 1938 tornou-se um "hino não oficial" do país, 
popularizando-se muito nos tempos de guerra que se seguiram. Parte da letra diz: "From the mountains / To the prairies / To the oceans / White with foam / God bless America / My home sweet home". ${ }^{4}$

Mas, assim como a bandeira, esse hino foi glosado pelo músico e cantor Woody Guthrie; ligado ao cancioneiro folk desde jovem, tornou-se famoso pelas letras de protesto depois da Grande Depressão, quando aderiu ao Partido Comunista. Em 1940, ele escreveu God Blessed America for Me, fazendo um contraponto mordaz ao hino. Mais tarde ele modificaria um pouco a letra, renomeada como This Land is Your Land, da qual reproduzimos um trecho: "When the sun came shining, and I was strolling / And the wheat fields waving and the dust clouds rolling / A voice was chanting, As the fog was lifting, / This land was made for you and me". ${ }^{5}$ Sempre com um violão com os dizeres "This machine kills fascists", os versos de Woody expunham a terra da promissão.

No entanto, afinal, que país era (é) esse? Quais encantos exerceu (exerce) aos que o conheceram (conhecem)? Quais as decepções ou revoltas que provocou (provoca) interna e externamente?

\section{“Quem é o americano, este novo homem"!}

John Hector St. John de Crèvecœur - um francês que escolhera viver em New York - na sua Letter III dos anos 1760 fez esta pergunta: "What then is the American, this new man? He is either a European, or the descendant of a European, hence that strange mixture of blood, which you will find in no other country". ${ }^{6}$ Este "novo homem" que gerou tais indagações seria mais tarde recuperado pela Literatura como um ser original, muito mais adequado aos embates de uma terra por construir que seus avós do Velho Mundo. Pode-se especular que em Crèvecœur confluíssem uma tradição puritana - associada a uma busca pela Terra Prometida, que mais tarde resultaria na doutrina do Destino Manifesto - e um pragmatismo burguês de políticos e pensadores que literalmente projetaram um país.

Com sua Declaração de Independência de quatro de julho de 1776, estes "novos homens" emergiam da Revolução Americana ${ }^{7}$ para a construção de uma nação que passava, antes que nada, pela sua identificação como "um povo". Dizem os membros congressistas dos Treze Estados:

Anos 90, Porto Alegre, v. 22, n. 41, p. 15-26, jul. 2015 
When in the Course of human events, it becomes necessary for one people to dissolve the political bands which have connected them with another, and to assume among the powers of the Earth, the separate and equal station to which the Laws of Nature and the Nature's God entitle them, a decent respect to the opinions of mankind requires that they should to declare the causes which impel them to the separation. ${ }^{8}$

Destacamos que, se era alegada uma legitimação divina, aparecia também em maiúsculas as Leis da Natureza! O "americano" político tinha sido gestado pela sua "natureza americana".

Para esse país tornado independente pelas armas "americanas", em dezessete de setembro de 1787, seus Founding Fathers ${ }^{9}$ assumiram a representação de "Povo dos Estados Unidos" quando escreveram uma Constituição que vige até os dias atuais. Já o seu Preâmbulo, clama por um apelo coletivo:

We the People of the United States, in Order to form a more perfect Union, establish Justice, insure domestic Tranquility, provide for the common defence, promote the general Welfare, and secure the Blessings of Liberty to ourselves and our Posterity, do ordain and establish this Constitution for the United States of America. ${ }^{10}$

Mais tarde a ratificação deste diploma passou pela elaboração da Bill of Rights - a Declaração de Direitos - formada por dez emendas, também elas em vigor atualmente. É à Primeira Emenda em que se atribuem os fundamentos da democracia "americana":

Congress shall make no law respecting an establishment of religion, or prohibiting the free exercise thereof; or abridging the freedom of speech, or of the press; or the right of the people peaceably to assemble, and to petition the Government for a redress of grievances". 11 
O "novo homem" inaugurava-se em nome da liberdade, da igualdade, dos direitos universais. Mas estes "americanos" não eram tão "iguais", ou tão "livres", ou não gozavam todos dos mesmos direitos. Neste projeto de nação em que os políticos dos ilustrados estados do Norte atraíram estrangeiros de todas as partes para suas grandes cidades, ao mesmo tempo em que lhes facilitaram o acesso às generosas terras do Oeste, conformavam-se campos de conflito: burgueses e operários nos centros urbanos, fazendeiros e indígenas, nos novos territórios. Por outro lado, conviviam com os aristocratas dos estados do Sul, com suas grandes plantations de algodão tocadas por escravos africanos, com cinturões de brancos pobres sitiantes. ${ }^{12}$ Os acertos de tantas disparidades se faziam com a expansão do país às custas do extermínio dos que fossem empecilho: povos indígenas, franceses, espanhóis, mexicanos... A doutrina do Destino Manifesto avançava as fronteiras dos Estados Unidos, mas o melting pot que formaria o "americano" decerto não incluía estes outros povos.

Lutas pelos direitos civis dos afrodescendentes, reconhecimento dos povos indígenas remanescentes, imigração clandestina de latino-americanos e orientais, imperialismo e opressão externos são ainda dilemas da sociedade estadunidense que não foram garantidos pelos diplomas da sua fundação. Ainda não sabemos o que é um americano, ou em que ele difere dos demais americanos. Afinal, que América é esta, dentro da nossa América?

\section{A outra América entre nós!}

O Curso de História da Universidade Federal do Rio Grande do Sul há muito tempo destaca como área de estudos a História da América. Em tempos mais pregressos, as disciplinas obrigatórias de História da América incluíam os conteúdos de História dos Estados Unidos, desde os tempos coloniais até os contemporâneos. Assim, era possível uma comparação entre os processos de colonização, as revoluções de independência e formações dos Estados nacionais, a inserção no capitalismo mundial etc. Observava-se, no entanto, que a História dos Estados Unidos merecia um destaque maior, até porque os temas relativos à História Contemporânea chamavam a atenção para uma superpotência cuja história de antanho não vinha sendo 
trabalhada com a intensidade merecida. Numa reunião de docentes que ministravam História da América na UFRGS, realizada em 1990, a professora Heloísa Jochims Reichel sugeriu a criação de uma disciplina específica de História dos Estados Unidos; os demais professores - Susana Bleil de Souza, Claudia Wasserman, Helen Osório e Cesar Augusto Barcellos Guazzelli - apoiaram esta proposta, que foi mais tarde referendada pelo Departamento de História.

Desde então, História dos Estados Unidos da América faz parte do currículo de disciplinas eletivas do Curso de História, mas há reparos a fazer. O primeiro deles diz respeito a uma dupla mudança na inserção dos conteúdos ministrados: aos tempos em que eles faziam parte dos programas de História da América, eram obrigatórios para todos os alunos do curso; no formato que vige desde 1990, eles se tornaram opcionais! Além disso, na medida em que História dos Estados Unidos da América é eletiva, os professores que a assumem têm também uma ampla liberdade de escolha em relação aos temas que desenvolvem. (História dos Estados Unidos da América já foi ministrada por Heloisa J. Reichel, Susana B. de Souza e Cesar A. B. Guazzelli, tanto de forma sucessiva como compartilhada.)

Em 2003, Cesar A. B. Guazzelli foi contemplado com Bolsa Produtividade do CNPq para desenvolver o projeto de pesquisa Senhores da guerra em espaços fronteiriços: o norte do México e o Rio da Prata na primeira metade do século XIX (c.1810-c.1850); este estudo comparativo inaugurava as pesquisas sobre História dos Estados Unidos na UFRGS. Neste mesmo ano, Guazzelli também ministrou pela primeira vez a disciplina de História dos Estados Unidos da América, realizando um corte temporal entre a Independência e o final do século XIX. A esse projeto, foram integrados dois acadêmicos do Curso de História que desde o ano anterior estavam associados aos estudos sobre fronteiras: Arthur Lima de Avila e Renata Dal Sasso Freitas. Fluentes em inglês, cada um deles tratou de um tema específico em relação ao espectro mais amplo da pesquisa: Arthur Avila assumiu a investigação sobre Fronteiras nos ensaios de Frederick Jackson Turner, cuja obra nunca era traduzida em português; Renata Freitas dedicou-se aos temas fronteiriços na obra de James Fenimore Cooper, quase toda ela inédita em português.

Os dois bolsistas deram continuidade aos seus trabalhos com investigações próprias derivadas destas atividades. Arthur Lima

Anos 90, Porto Alegre, v. 22, n. 41, p. 15-26, jul. 2015 
de Avila realizou o Mestrado no Programa de Pós-Graduação em História da UFRGS como bolsista do CNPq, defendendo em 2006 a dissertação intitulada E da Fronteira veio um Pioneiro: a "frontier thesis" de Frederick Jackson Turner (1861-1932), sob a orientação de Cesar Augusto Barcellos Guazzelli. Ingressando no Doutorado do mesmo Programa, Arthur Ávila desenvolveu sua Tese Território contestado: a reescrita da bistória do Oeste norte-americano (c.1985-c.1995), com apoio do CNPq, ainda sob orientação de Cesar Guazzelli. Durante o Doutorado, realizou estágio na John Hopkins University. Em 2011, o trabalho foi contemplado com o Prêmio CAPES de melhor Tese em História de 2010.

As pesquisas sobre Cooper renderam a Renata Dal Sasso Freitas a dissertação de Mestrado Páginas do Novo Mundo: um estudo comparativo entre José de Alencar e James Fenimore Cooper na formação dos Estados nacionais brasileiro e norte-americano no século XIX, realizada no Programa de Pós-Graduação em História da UFRGS; ela recebeu bolsa do CNPq, sendo concluída em 2008, sob orientação de Cesar Guazzelli. Neste mesmo ano, Renata Freitas iniciou seu Doutorado no Programa de Pós-Graduação em História Social da Universidade Federal do Rio de Janeiro; em 2012, concluiu a Tese intitulada "Love of country": os romances históricos de James Fenimore Cooper sobre a Guerra de Independência dos Estados Unidos (1821-1824), com apoio do CNPq; nesse período estagiou na Yale University, em função de suas pesquisas.

Atualmente, Cesar Augusto Barcellos Guazzelli, Arthur Lima de Avila e Renata Dal Sasso Freitas coordenam o projeto de pesquisa América: identidades e alteridades: a escrita da História da América Hispânica nos Estados Unidos (c.1900-c.1930) apoiado em Edital Universal do CNPq. Essa pesquisa reúne diversos pesquisadores e bolsistas da UFRGS e de outras universidades, todos com investigações relacionadas e temas de História dos Estados Unidos da América. ${ }^{13}$

\section{A outra América em Revista!}

Salientamos até agora algumas controvérsias que gera a História dos Estados Unidos, esta "outra América" que dá nome a um país tão diverso das demais nações americanas. Este irmão do Norte, cuja

Anos 90, Porto Alegre, v. 22, n. 41, p. 15-26, jul. 2015 
cultura de massas penetrou com uma intensidade talvez maior que sua influência na política ou sua dominação econômica imperialista, recebe atenções mínimas da historiografia nacional. Nesse sentido, nossa intenção de organizar este dossiê para a revista Anos 90 buscou cumprir uma dupla missão: 1) dar continuidade a um campo de conhecimento que vem se afirmando entre nós já há algum tempo; 2) apresentar para os historiadores que a História dos Estados Unidos tem uma grande possibilidade de se desenvolver em nosso meio.

Para este número da revista Anos 90, compusemos este dossiê com seis artigos inéditos, abordando aspectos históricos bem variados dos Estados Unidos da América.

O primeiro artigo tem como título A Quem Pertence o Passado Norte-americano? A controvérsia sobre os National History Standards nos Estados Unidos (1994-1996), de autoria do professor Arthur Ávila (UFRGS). Este texto trata da controvérsia pública sobre os National History Standards, um conjunto de propostas que visavam a auxiliar na reforma do Ensino Básico nos Estados Unidos, entre 1994 e 1996. No texto, enfatizam-se as respostas dos setores conservadores às diretrizes propostas, especialmente sua rejeição àquilo que consideravam um "sequestro da história" pelas hostes "multiculturais", "politicamente corretas" e "antiocidentais". Com isso, argumenta-se que tais setores buscavam a construção de um passado estável e sem conflitos justamente como contraponto a um presente que se apresentava cada vez mais instável e conflituoso, assegurando, assim, uma ideia bastante limitada sobre quem eram os personagens da história norte-americana e o que ela deveria significar.

Segue-se Os Estados Unidos entre o nacional e o transnacional: o saber produzido pela circum-navegação científica da U. S. Exploring Expedidion (1838-1842), de autoria da professora Mary Anne Junqueira (USP). Aqui trata-se de analisar alguns aspectos do conhecimento moderno expresso no relato de viagem da primeira circum-navegação científica, U. S. Exploring Expedition, entre 1838-1842. Os conjuntos de saberes constituídos pela expedição estiveram entre a afirmação nacional e os aspectos transnacionais próprios da época. Revela-se o propósito norte-americano no que diz respeito à inserção de quadros do país na rede de conhecimento liderada pelos europeus, discutindo com os seus pares do velho continente, mas também concorrendo com eles.

Anos 90, Porto Alegre, v. 22, n. 41, p. 15-26, jul. 2015 
O trabalho seguinte é de autoria do professor Vitor Izecksohn (UFRJ) e tem como título $A$ experiência miliciana norte-americana: antimilitarismo ou pragmatismo? Nesse artigo, o autor discute a experiência miliciana nas colônias inglesas da América do Norte e nos Estados Unidos durante a primeira república. Enfatizo o papel do antimilitarismo como principal aspecto da experiência militar anglo-americana. Relaciono essa perspectiva à aversão ao despotismo, derivada da tradição política inglesa e ao controle civil sobre os militares. Sublinho as dificuldades encontradas para a criação de um exército profissional e os problemas de coordenação entre o poder central e as autoridades locais e estaduais.

$\mathrm{O}$ artigo de Valeria Lourdes Carbone (UBA) tem como título El Movimiento afro-estadounidense contra el Apartheid sudafricano: un reflejo de la luch a de la comunidad negra a nivel doméstico y su impacto sobre la politica exterior de los EE.UU. Esse texto tem como proposta analisar como - e em que medida! - o ativismo político afro-estadunidense contra o Apartheid sul-africano, após décadas de militância e organização, passou a influenciar as relações diplomáticas entre os Estados Unidos e a África do Sul. Isto permite ver como o movimento afro-americano foi recebido pelo governo Reagan; além de observar como qual era a real influência que aquele movimento podia ter ao desafiar certos aspectos da política externa do governo, destaca-se também a possibilidade de canalizar demandas próprias e reivindica-las internamente.

O texto Sobrevoando histórias: sobre indios e historiadores no Brasil e nos Estados Unidos foi escrito por Soraia Sales Dornelles e Karina Moreira Ribeiro da Silva e Melo, da Universidade Estadual de Campinas (UNICAMP). As duas historiadoras abordam aspectos similares entre as produções brasileira e estadunidense sobre os respectivos grupos indígenas. Salientam que em ambos os casos as produções históricas feitas sobre os habitantes nativos tiveram importância objetiva nas políticas públicas relativas a eles. Destacam ainda que muitas influências de natureza complexa agem na formulação de conhecimentos sobre os povos indígenas do Brasil e dos Estados Unidos. O objetivo das autoras é perseguir uma abordagem comparativa entre as construções dos discursos históricos sobre os indígenas nos dois países, buscando, a partir disso, mapear os possíveis intercâmbios científicos sobre o tema. 
Martha De Cunto (UBA) escreveu Chase-Riboud: Sally Hemings: Oralidad, escritura y la resignificación del passado, em que analisa o romance histórico de Chase-Reboud dentro de tradição literária negra. O trabalho relaciona o romance com as primeiras narrativas dos escravos, mostrando as continuidades e ruptura. Indaga sobre as representações dos principais personagens: Langdon, a escritura; Sally, a oralidade; e James, a cultura e a comunidade negra. $\mathrm{O}$ texto discute a legitimidade, o valor histórico e a veracidade dos discursos escritos, assim como aborda a desestabilização do binário "realidade ficcional" e "realidade" histórica, denunciando a forma como a historiografia dos brancos dominadores apresenta os negros marginalizados.

O último artigo, Entre Cabanas e Diligências: os Fronteiriços na Western Fiction de Bret Harte e Ernest Haycox, é de autoria conjunta de Cesar Guazzelli e Renata Freitas (UFRGS). O texto evidencia como a fronteira americana em seu avanço inexorável para Oeste produziu obras ficcionais muito carregadas de emoção, mesmo passados os tempos épicos dos pioneiros. Mais que isso, elas recriaram os seus dramas fora daquelas paisagens ocupadas pelos grandes rebanhos de gado e seus cowboys, mas justamente nos núcleos civilizatórios que já se haviam instalado no Oeste. A mitologia dos pioneiros mudava para uma realidade menos glamourizada, mas talvez mais verossímil. Assim, o que propomos é uma leitura comparada de dois contos que se reportam ao avanço da fronteira "civilizatória" para o Oeste: The Outcasts of Poker Flat, de Bret Harte, escrita em 1868 (HARTE, 2001) e Stage to Lordsburg, de Ernest Haycox, escrita em 1939.

Essas são algumas visões sobre a História dos Estados Unidos, para que talvez - parafraseando Crèvecœr - compreendamos um pouco melhor quem é aquele "novo homem", e se este outro "americano" está tão distante assim de nós.

\section{Notas}

${ }^{1}$ Esta fala aconteceu na abertura do Ciclo de Cinema - Curso de Extensão em Cinema, História e Educação US A não abusa! Os Estados Unidos da América em Tempos de Guerra. No mesmo ano, esta conferência de Karnal foi publicada como texto: Identidade e Guerra: Estados Unidos da América e os Conflitos (GUAZZELLI, Cesar Augusto Barcellos et al. Tio Sam Vai à Guerra. Porto Alegre: Letra \& Vida, 2010, p. 9-16).

Anos 90, Porto Alegre, v. 22, n. 41, p. 15-26, jul. 2015 
${ }^{2}$ Durante as guerras de independência, a expressão "americano" foi usada por todo continente em oposição aos colonizadores. Também não custa lembrar que a América do Norte - vista aqui como um subcontinente! - inclui o Canadá e o México. ${ }^{3}$ Esta organização política pode ser acompanhada pelas publicações do jornal The Federalist, mais tarde reunidas em um livro homônimo: HAMILTON, Alexander; MADISON, James; JAY, John. O Federalista. Brasília: Editora da UnB, 1984. 4 "Das montanhas / Para as pradarias / Para os oceanos / Branco com espuma / Deus abençoe a América / Meu lar doce lar". Tradução nossa.

5 "Quando o sol apareceu brilhando, e eu estava passeando / E os campos de trigo ondulando $e$ as nuvens de poeira rolando / Conforme a fumaģa se levantava uma voz cantava / Esta terra foi feita para você e para mim". Tradução nossa.

6 "Quem é afinal o americano, esse novo homem? É europeu ou descendente de europeu, e daí aquela estranba mistura de sangue que não é encontrada em nenbum outro país". Tradução nossa. Uma série de cartas escritas por Crèvecoeur foram reunidas e publicadas em 1782, como Letters from na American Farmer. Ver: VANSPANCKEREN, Kathryn. Outline of American Literature. Dules (VA): United States Departament of State, 1994, p. 18. ${ }^{7} \mathrm{O}$ historiador marxista estadunidense Aptheker não duvida em destacar a Revolução Americana como "uma daquelas grandes guerras realmente revolucionárias". APTHEKER, Herbert. Uma Nova História dos Estados Unidos: a Revolução Americana. Rio de Janeiro: Civilização Brasileira, 1969, p. 17.

8 "Quando no Curso dos eventos bumanos torna-se necessário para um povo dissolver os laços políticos que o tem ligado a outro, e assumir, entre os poderes da Terra, estatuto igual e separado que lhe asseguram as Leis da Natureza e de Deus, o decente respeito às opiniões da bumanidade requer que sejam declaradas as causas que os impeliram à separaşão". Tradução nossa. FOUNDING FATHERS. The Declaration of Independence and The Constitution of the United States of America. New York: SoHo Books, 2012.

${ }^{9}$ Pais Fundadores são chamados os congressistas que elaboraram a Constituição dos Estados Unidos e as Emendas que formam a Declaração de Direitos do Cidadão. 10 "Nós, o Povo dos Estados Unidos, a fim de formar uma União mais perfeita, estabelecer a Justiça, assegurar a Tranquilidade interna, prover a defesa comum, promover o Bem-Estar geral, e garantir para nós e para os nossos Descendentes as Bênçãos da Liberdade, ordenamos e estabelecemos esta Constituição para os Estados Unidos da América". Tradução nossa. FOUNDING FATHERS, op. cit.

11 "O congresso não deverá fazer qualquer lei a respeito de um estabelecimento de religião, on proibir o seu livre exercício; on restringindo a liberdade de expressão, ou da imprensa; on o direito das pessoas de se reunirem pacificamente, e de fazerem pedidos ao governo para que sejam feitas reparações de queixas". Id. Ibid.

${ }^{12} \mathrm{O}$ contraste entre o Norte capitalista e o Sul escravocrata levariam o país à trágica Guerra da Secessão. Para Barrington Moore, ela teve tanta importância quanto as grandes revoluções capitalistas do século XVIII. MOORE JR., Barrington. As origens

Anos 90, Porto Alegre, v. 22, n. 41, p. 15-26, jul. 2015 
sociais da ditadura e da democracia. São Paulo: Martins Fontes, 1983. Sobre o tema, ver também: KOSSOK, Manfred et al. Las Revoluciones Burguesas. Barcelona: Crítica, 1983. ${ }^{13}$ Os docentes colaboradores são os seguintes: Teresa Cribelli, Ph.D. em História pela Johns Hopkins University, professora de História na University of Alabama; Fabrício Pereira Prado, Ph.D. em História Latino-Americana pela Emory University, professor de História na Roosevelt University, USA; Mariana Flores da Cunha Thompson Flores, Doutora em História pela Pontifícia Universidade Católica do Rio Grande do Sul (PUCRS), com estágio doutoral na Universitat Pompeu Fabra, de Barcelona, professora da Universidade Federal de Santa Maria (UFSM); Joana Bosak de Figueiredo, Mestre em História e Doutora em Literatura Comparada pela UFRGS, com estágio doutoral na Universitat de Barcelona, professora de História da Arte na UFRGS; Susana Bleil de Souza, Doutora em História pela Université de Paris X - Nanterre, de professora de História na UFRGS e professora convidada da Universidad de la República de Montevidéu; Carla Menegat, Doutoranda em História na UFRGS, com estágio doutoral na Universidade Federal do Rio de Janeiro (UFRJ), professora no Instituto Federal de Educação, Ciência e Tecnologia Sul-Rio-Grandense (IFSUL); Rafael Hansen Quinsani, Doutorando em História na UFRGS.

\section{Referências}

APTHEKER, Herbert. Uma Nova História dos Estados Unidos: a Revolução Americana. Rio de Janeiro: Civilização Brasileira, 1969

FOUNDING FATHERS. The Declaration of Independence and The Constitution of the United States of America. New York: SoHo Books, 2012

HAMILTON, Alexander; MADISON, James; JAY, John. O Federalista. Brasília: Editora da UnB, 1984.

KARNAL, Leandro. Identidade e Guerra: Estados Unidos da América e os Conflitos. In. GUAZZELLI, Cesar Augusto Barcellos et al. Tio Sam Vai à Guerra. Porto Alegre: Letra \& Vida, 2010. p. 9-16.

KOSSOK, Manfred et al. Las Revoluciones Burguesas. Barcelona: Crítica, 1983

MOORE Jr., Barrington. As origens sociais da ditadura e da democracia. São Paulo: Martins Fontes, 1983.

VANSPANCKEREN, Kathryn. Outline of American Literature. Dules (VA): United States Departament of State, 1994

Anos 90, Porto Alegre, v. 22, n. 41, p. 15-26, jul. 2015 